\title{
Is Metaphysics Hyper-Physics or Over-Physics? Evaluating it with Mathematical Paradigms
}

\author{
Şemsettin DURSUN*
}

\author{
Cahit TAŞDEMIR ${ }^{* *}$
}

Received: 25 June 2015

Accepted: 29 August 2015

\begin{abstract}
Metaphysics is the most fundamental, comprehensive and extensive research field among all disciplines and investigating fields. It is the most fundamental field since it deals with ultimate and superior nature of the issues that have been the subject of other research areas. It is the most comprehensive field since it deals with questions and problems valid for all subjects and fields exceeding the private science boundaries, and questions related with existence and reality, actual and potential existence and ultimate causality that metaphysician tackle with (Cevizci, 2003). In this study, initially, what the term of metaphysics is with its relevant fields, its relation to the science in general and to mathematics and logic in particular. Afterwards, by which expressions hyper-physics or over-physics are more convenient to be described was evaluated in terms of several mathematical concepts and mathematical translation paradigms and discussed within this context.
\end{abstract}

Keywords: mathematics, meta, physics, metaphysics, paradigm

\section{Extended Abstract}

In general, the term of Metaphysics is expressed with a word of hyperphysics in social life and scientific word. The word of hyperphysics is formed as a combination of words of physics and hyper. Etymological meaning of meta word which is the prefix of Metaphysics term and the prefixed terms form different disciplines. These terms are expressed by Cevizci (2003) as followings;

Meta: In western languages, it is a term that refers to exceeding and dealing with anything at higher levels. When put in front of a word or certain discipline, meta expresses the research, examination and solution of fundamental properties and problems of that discipline.

Metaphysics: Metaphysics is the most fundamental, comprehensive and extensive research field among all disciplines and investigating fields. It is the most fundamental field since it deals with ultimate and superior nature of the issues that have been the subject of other research areas. It is the most comprehensive field since it deals with questions and problems valid for all subjects and fields exceeding the private science boundaries, and questions related with existence and reality, actual and potential existence and ultimate causality that metaphysician tackle with.

\footnotetext{
${ }^{*}$ Corresponding Author. Assoc. Prof. Dr., Batman University, Batman, Turkey, dursun72@gmail.com.

** Assist. Prof. Dr., Bitlis Eren University, Bitlis, Turkey, ctasdemir@beu.edu.tr
}

\section{Citation Information}

Dursun, Ş. \& Taşdemir, C. (2016). Metafizik, fizikötesi mi fiziküstü mü? Matematiksel paradigmayla değerlendirme. Kuramsal Eğitimbilim Dergisi [Journal of Theoretical Educational Science], 9(1), 130-145. 
As it can be understood from the descriptions mentioned above, when the term of meta is used as a prefix of any discipline or term, it gives a top ID to fundamental parameters of this discipline or the term without spoiling "its essence" and "World wideacceptance". The term expressed with prefix meta does not contribute a meaning of "hyper" or "translation", however it contributes to it with the meaning of "upper" or “extent” or “on”.

Purpose and Significance: The purpose of this study is to examine conceptional aspect of term of metaphysics and within this context, its relevance to the other fields and its relation to the science in general and to mathematics and logic in particular were dealt with and also by which expressions hyper-physics or over-physics are more convenient to be described was evaluated. In the research conducted in this context, assessments were carried out to understand and determine the term of metaphysics and its properties with several mathematical concepts and mathematical translation paradigms.

Methods: In this study, descriptive and normative qualification methods were conducted. A reseacher/person who investigates studies in Metaphysics field can come across quite different descriptions and definitions related to metaphysics. These descriptions and definitions could be descriptive modifiers and definitions which show/reveal the research of philosopher in Metaphysics field or could be normative descriptions and definitions that represent what they do.

Results: When the term of meta is used as a prefix of any discipline or word, it gives a higher ID to fundamental parameters of this discipline or the term without spoiling "its essence" and "World wide-acceptance". The term expressed with prefix meta contributes a meaning of "upper" or "extent” or "on" and does not contribute a meaning of "hyper" or "translation".

It is clearly seen that the term of metaphysics cannot be described by the term of hyperphysics, but it can be described by the term of overphysics.

Discussion and Conclusion: As seen in Figure 2.1, in accordance with the mathematical translation principle, it is observed that the circles of $(x-h)^{2}+(y-k)^{2} \leq r^{2}$ [whose center and radius are $(h, k)$ and $r$, respectively] and its translation by the $x^{2}+y^{2} \leq$ $r^{2}$ circle defined with basic function of $(0,0)$ centered and with radius of $r$ are completely discrete sets and the intersection of these sets is an $\varnothing$ (empty) set. Similarly, when Figure 2.2 is examined, it is seen that $\mathrm{p}(\mathrm{x}, \mathrm{y})$ point on the plane of $\mathrm{x}-\mathrm{y}$ was translated to $\mathrm{Q}(\mathrm{x}+\mathrm{h}, \mathrm{y}+\mathrm{h})$ point by the translation function. It is apparent that $\mathrm{Q}(\mathrm{x}+\mathrm{h}, \mathrm{y}+\mathrm{h})$ points which are translated by $\mathrm{p}(\mathrm{x}, \mathrm{y})$ point are discrete sets and the intersection of these sets is empty (Ø) set. If the sets are discrete, their intersection is empty. Thereby, they do not have any point in common. Namely, Physics $\cap$ Metaphysics $\neq \varnothing$

Similarly, translation function in Figure 2.4 forms a geometric illustration by matrice. 
Here, $\vec{u}=(1,-4)$ vector transforms $\mathrm{ABC}$ triangle whose corners are $\mathrm{A}(1,4), \mathrm{B}(3,6)$ and $\mathrm{C}(5,3)$ into $A^{\prime} B^{\prime} C^{\prime}$ triangle whose corners are $A^{\prime}(2,0), B^{\prime}(4,2)$ and $C^{\prime}(6,1)$ by the $\Delta$

translation function of $T_{\vec{u}}:(x, y) \rightarrow(x+1, y-4)$. It will be $(A B C) \cap\left(A^{\prime} B^{\prime} C^{\prime}\right)=\varnothing$. These triangles are discrete.

Here, it is assumed that $\mathrm{ABC}$ triangle refers to physics whereas $A^{\prime} B^{\prime} C^{\prime}$ refers to metaphysics. According to this, when translation functions in Figure 2.2, Figure 2.3 and Figure 2.4 are taken into account in accordance with mathematical paradigm and when the etymological meaning of meta prefix is examined, it is seen that using the term of meta as a prefix of any discipline, it gives a higher ID to fundamental parameters of this discipline or the term without spoiling "its essence". This situation clearly shows that the term of hyperphysics cannot be defined instead of metaphysics.

On the other hand, the intersection of $A=x^{2}+y^{2} \leq r^{2}$ and $B=(x+h)^{2}+(y+k)^{2} \leq \rho^{2}$ circles given in Figure 2.5 is not empty (Ø). Namely, $A \cap B=A=x^{2}+y^{2} \leq r^{2} \neq \varnothing$. Thereby, $B$ set includes A set or B set is super-set of A set. If it is assumed that a set refers to physics, B set will refer to metaphysics. Because, B set has a state of including A set. From here, it is clearly seen that the term of metaphysics can only be defined with the term of overphysics. Accordingly, the term of hyperphysics does not meet the meaning of metaphysics. As seen in Figure 2.6 (a), Figure 2.6 (b) and Figure 2.7, the intersection of the linear independent vectors in the space is empty, namely there is no point of them in common, whereas the intersection of the linear dependent vectors is not empty. It is seen that the meaning of the term of metaphysics can only be maintained with the term of overphysics when the relation between the terms of physics and metaphysics is examined in terms of linear dependency and linear independency. 


\section{Metafizik, Fizikötesi mi Fiziküstü mü? Matematiksel Paradigmayla Değerlendirme}

\author{
Şemsettin DURSUN ${ }^{*}$
}

Makale Gönderme Tarihi: 25 Haziran 2015

\author{
Cahit TAŞDEMIR**
}

ÖZ: Bu çalışmada öncelikle metafizik kavramının ne olduğu üzerinde durulmuştur. Daha sonra metafizik üzerine yapılan araştırmalar, metafiziğin genelde bilimle özelde de matematik ve mantıkla ilişkisi tartışılmıştır. Ayrıca metafizik kavramının fizikötesi ya da fizik üstü ifadelerinden hangisi ile ifade edilmesinin daha uygun olacağı, çeşitli matematiksel kavramlar ve matematiksel öteleme paradigması aracıllı̆ıyla değerlendirilmiş ve bu çerçevede tartışılmıştır. Çalışmada, metafizik kavramının anlaşılması ve özelliklerinin belirlenmesinde, matematiksel kavramlar ve öteleme paradigmasından yararlanılmış ve bu kapsamdaki örneklere ve tartışmalara yer verilmiştir. Sonuç olarak, eğer metafizik kavramı fizikötesi şeklinde tanımlanırsa belirtilen matematiksel paradigmayla açılanan öteleme fonksiyonu prensibi gereğince, fizik ile metafizik kavramlarının arakesitinin boş olacağı, dolayısıyla bu iki kavram arasında hiçbir ortak nokta olmayacağı, halbuki fizik ile metafizik kavramları arasında hem kavramsal hem de pratiksel anlamda ortak noktalar olduğu, buradan da fizik ile metafizik kavramları ayrık kavramlar olmadığından metafizik kavramının fizikötesi şeklinde tanımlanmasının hatalı olduğu görülmüştür.

Anahtar kelimeler: matematik, meta, fizik, metafizik, paradigma

\section{Giriş}

\section{Metafizik ve Araştırma Alanı}

Metafizik terimi, Aristoteles'in (Aristo) eserlerinden birinin başlı̆̆ından hareketle ortaya çıkmıştır. Aristo, metafizik terimini kendi çalışmalarında kullanmamasına rağmen, bu terim Aristo'nun takipçileri tarafından daha sonradan gündeme getirilmiş ve Aristo'nun çalışmaları, Yunanca'da "Metaphusika" İngilizce'de ise "Metaphysics" başlıklı özel bir kitapta toplanmıştır (Carroll \& Markosian, 2013).

Aristo'nun ilgili eserinde metafizik başlığının ardışık kullanımı, Aristo'nun takipçilerini eserde yapılan niteleme ve tanımlamaları, metafizik olarak adlandırmaya yönelik bir düşünceye sevk etmiştir. Bu bağlamda, metafizik kavramını tanımlamak kolay olmayabilir. Zira, metafizik alanındaki çalışmaları inceleyen bir kişi/araştırmacı, metafiziğe yönelik oldukça farklı nitelemeler ve tanımlamalarla karşılaşabilir. Bazen bu niteleme ve tanımlamalar, metafizik alanında çalışan felsefecilerin yaptıklarını ortaya koyan/gösteren betimsel niteleme ve tanımlamalar olabilir. Bazen de felsefecilerin, metafizik üzerine çalışırken ne yaptıklarını ortaya koyan girişimleri temsil eden normatif niteleme ve tanımlamalar olabilir.

Betimsel ve normatif bu nitelemeler ve tanımlar, metafiziğin konu alanının ve yönteminin farklı yönlerini ortaya çıkarmaktadır. Farklı alanlarda çalışan araştırmacılar, metafiziğin bu farklı niteleme ve tanımlamalarının farklı disiplinler olduğuna yönelik bir izlenime sahip olabilir (Loux, 2004). Metafizik, genel anlamda i) gerçekliğin ve bilimin mantıksal temellerinin bir çalışması, ii) gerçekliğin teorisi veya var olan bilgimizle gerekçelendirilen gerçekliğe ilişkin en yüksek genelleme (Marvin, 1912)

\footnotetext{
* Sorumlu Yazar. Doç. Dr., Batman Üniversitesi, Batman, Türkiye, dursun72@gmail.com

*** Yrd. Doç. Dr., Bitlis Eren Üniversitesi, Bitlis, Türkiye, ctasdemir@beu.edu.tr
} 
veya iii) gerçekliğin doğasına ilişkin temel sorularla ilgilenen felsefenin branşı (Carroll \& Markosian, 2013). ) olarak ele alınabilir

Diğer taraftan, metafiziğin doğasına yönelik yapılan tartışmalar, uzun bir tarihsel geçmişe dayanmaktadır. Filozofların, iki bin yıldan fazla süren uğraşı ve çabaları sonucunda, metafiziğin konusu ve yöntemine yönelik farklı görüşler ortaya çıkmıştır. $\mathrm{Bu}$ nedenle, metafiziğin tarihsel süreci göz önüne alındığında, metafiziğin bir tek konu alanını ve yöntemini tanımlamak zor görünmektedir. Bununla birlikte, Aristo'da metafiziğin ne olduğuna yönelik iki farklı görüş ön plana çıkmaktadır. Birincisi metafizik, "ilk nedeni tanımlamayla" ilgilenen bölümlere ayrışmış bir disiplindir, özelde bu Allah'1 veya Hareket Etmeyen Hareket Ettirici’yi incelemektir. İkincisi ise varlık veya varoluş perspektifinden nesneleri inceleyen ve var olmanın genel özelliklerini belirlemeye çalışan evrensel veya genel bir disiplindir (Loux, 2004). Buna göre metafizik, felsefenin en önemli disiplinlerinden biri olan ontoloji yani varlık felsefesi anlamına gelir. "Var olan varlık" ifadesi manidar bir ifade olup, varlık, her ne şekilde varsa fizik veya metafizik içindedir. Buradan metafiziğin, fiziği reddetmediğini hatta kapsadığı görülebilir (Yaldır ve Kiraz, 2008). İlk bakışta, metafiziğin yukarıda bahsedilen iki kavramsallaştırılması arasında bir farklılığın olduğu düşünülebilir. Yani, bir disiplinin hem bölümlere ayrılmış hem de evrensel bir disiplin olarak düşünülebileceğini anlamak zor olabilir. Aristo, metafiziğin konu alanına yönelik bu ayrımın farkına varmış ve bu ayrımın sadece görünüşte olduğuna yönelik açıklamalarda bulunmuş ve bu iki farklı nitelemenin aslında aynı disiplini temsil ettiğini belirtmiştir. Buna karşılık, 17. ve 18. yüzyılın rasyonalist felsefecileri metafiziğin eğilimini genişletmişlerdir. Bu filozoflar, sadece Allah'ın doğası ve varlığı ile ilgilenmemiş aynı zamanda ruhun ölümsüzlügü ve arzuların serbestliği ile akıl ve beden arasındaki farklılıkları da incelemişlerdir (Loux, 2004).

\section{Metafizik ve Bilim İlişkisi}

Metafizik, öncelikli olarak gerçekliğin doğası, epistemoloji ve estetikle ilgilenir. Ancak, metafiziğin sadece bu konu alanları ile ilgisi kaçınılmaz düzeyde değildir. Bu bağlamda; metafizik, diğer disiplinlerden nasıl ayrışır? Metafizik, a priori yöntemleri aracılığıyla fizik ve bilimin diğer dallarından kısmen ayrışmaktadır. Bilim, iddialarını gözlem ve deneylere dayandırırken, metafiziğin iddiaları bazen tesadüflere dayalı olarak laboratuar sonuçlarından ziyade çalışma bulgularına dayalı olabilir. Metafizik, sadece $a$ priori yöntemleriyle değil aynı zamanda ilgi alanlarının genelliği bakımından felsefeden de ayrışmaktadır. Felsefe, duygu ve düşünme aracılığıyla gerçekliğin adalet ve mutluluk gibi yönleriyle ilgilenirken; metafizik, değer, söz veya akıl ile gerçekliğin en genel özelliklerine odaklanır (Fine,2012). Metafiziğin kavramları, açık ve şeffaf olma özellikleri ile de diğer bilimlerden ayrışmaktadır. Yani; bir kavram ve bu kavramın ne olduğuna yönelik imgeler arasındaki boşluk anlamlı olmadığı zaman bu kavram şeffaftır. Örneğin, su kavramı ile suyun iki hidrojen ve bir oksijen atomundan meydana geldiğini gösteren $\mathrm{H}_{2} \mathrm{O}$ kimyasal formülü arasında anlamlı bir farklılık vardır. Yani, "Su, $\mathrm{H}_{2} \mathrm{O}$ 'dur." cümlesi suyun doğasına yönelik açık ya da gizli bir referans vermeden suyun doğasını tanımlamaktadır. Diğer taraftan, "Suyun doğası, $\mathrm{H}_{2} \mathrm{O}$ 'dur." cümlesi ise 
suyun doğasına yönelik açık ya da gizli bir referans vermektedir. Bu nedenle, su kavramı şeffaf bir kavram olarak değerlendirilmeyebilir. Fakat, "Suyun doğası, $\mathrm{H}_{2} \mathrm{O}$ 'dur." cümlesinde, su kavramının özdeşliği ile su kavramıyla bağlantılı özdeşlik arasında anlamlı bir farklılık yoktur. $\mathrm{Bu}$ cümle, sadece suyun doğasının $\mathrm{H}_{2} \mathrm{O}$ olduğunu içermez. Aynı zamanda, "Eğer su $\mathrm{H}_{2} \mathrm{O}$ ise o zaman suyun doğası, $\mathrm{H}_{2} \mathrm{O}$ 'dur." şeklinde bir mantıksal çıkarıma da yol açar. Bu bağlamda, metafiziğin kavramları suyun doğasına referans vermeyen kavramlardan ziyade suyun doğasına referans veren özdeşlik bağlantısına dayalı a priori kavramlara daha çok benzemektedir. Bu kapsamda metafizik, sadece gerçeklik için değil aynı zamanda gerçekliğin doğası için de bir temel oluşturmayı hedefler (Fine, 2012). Bu bağlamda metafizik, teoriye dayalı bir disiplindir. Diğer taraftan, sanata dayalı bilimler, ürünlerle ilgilenirken, ekonomi, etik ve politika gibi pratiğe dayalı çeşitli bilimler ise insan davranışlarının eğilimini açıklamaya odaklanmıştır (Loux, 2004). Etik, estetik, epistemoloji ve diğer tüm felsefe dalları, fizik, biyoloji, kimya ve diğer tüm bilimler, belli türden varlıkları doğrudan veya dolaylı olarak konu edinirler. Bu alanların her biri için konu edildikleri varlıkların en genel özelliklerinin araştırılması, özel bir metafizik soruları alanını oluşturur (Taşdelen, 2013). Özel birimlerin konuları, belli varlık türleridir. Örneğin, fiziğin konusu fiziksel nesne türü, biyolojinin konusu canlı nesne türü, psikolojinin konusu ise zihinsel nesne türüdür. Biçimsel bir bilim olan matematiğin konusu ise soyut matematiksel nesne türüdür. Buna karş1lık ontoloji anlamındaki metafiziğin konusu ise var olan ve var olabilen şeylerin tümü olup (Gutenberg, 2013) gerçeklik anlayışını araştırmaya ve sorgulamaya odaklanmıştır. Bu bağlamda metafizik, matematik ve fen bilimleri ile bağdaşır. Bu kapsamda metafizik, öncelikli olarak aritmetikte soyut kavramlar ve süreçlerle, geometride ise sürekli kavramlarla ilgilenir. Daha sonra, dünyayı meydana getiren materyal ve fiziksel varlıkların (canlı ve cansız) doğasına ve yapısına odaklanır. Metafizik ve konu alanı arasındaki bu ilişki, metafiziği ilgi çekici bir konuma getirmiştir (Loux, 2004).

\section{Matematik, Mantık ve Metafizik İlişkisi}

Matematik için temel bir yöntem geliştirme yaklaşımları, matematiğin "bütün bilimlerin en mükemmeli” (Lakatos, 1986), "bütün bilimlerin anası" (Mura, 1995, s. 390), "bütün bilimlerin kraliçesi” (McGinnis, 1996, s. 17) ve "kendi başına bir bilim" (Mura, 1995, s.390) gibi elitist bir bakışla matematiği, hatalardan arınmış bir disiplin olarak göstermeye çalışmıştır. Diğer taraftan, bazı filozoflar da matematiğin a priori olduğu; yani kusursuz bir girişim olduğu, metodolojisinin kusursuz biçimde ortaya konabileceği ve gelişiminin formel ve evrensel bir sistemle formüle edilebileceğine yönelik dogmatik yaklaşımı sorgulamaya başlamışlardır. Bunun üzerine matematiğin, kusurlu, deneysel veya yarı-deneysel bir disiplin olduğu düşüncesi ortaya çıkmıştır (Handal, 2009). Metafizik ise bilginin nihai görüşünün incelenmesini, varlığın ve değişimin nihai nedenleri ve evrenin karşılıklı ilişkilerini belirleyen düzenlilik ilkesini içerir (Carter, 2003). Bu nedenle, varlığın tarzını ve özünü tayin etmek, metafiziğin (ilk felsefenin) işidir. Bu bakımından metafizik, şekil ve maddeden mürekkep olan tabiatı değil, şekli inceler. Aristo'ya göre, hareketsiz bir cevher varsa, bu cevherin bilgisi ilk 
felsefe olmalıdır ve o, ilk olduğundan dolayı da küllidir (Taşdelen, 2013). Mantık, tümdengelim ya da tümevarımcı çıkarım ilkelerini araştıran bir bilim iken; matematik, sembollerle ifade edilen nicelikler arasındaki ilişkilerin ve biçim ve şekiller arasındaki bağlantıların (ve boyutların) sistematik bir incelemesi olarak ifade edilebilir. Bir matematiksel formül, bir veya daha fazla değişkenden hareketle elde edilebilen bir değişkenin değerinin ilişkisini sembolik biçimde gösterir. Çoğu matematiksel teorem; matematiksel formüller içine gömülü bilimsel sonuçlar olarak gösterilir. Böylece, bilimde matematiğin kullanımı, evrenin kurallarının matematiksel ilkelere göre işlediğini kabul etmek anlamına gelmektedir. Matematik, evrenin işleyişine ilişkin bu önemli etkisi ile güçlü bir metafiziksel bileşene sahiptir. Hem matematik hem de mantık, problem çözme sistemleridir ve fizik veya metafizikte görülen sorunları açıklığa kavuşturmak/çözmek için kullanılabilir (Carter, 2003).

Diğer taraftan, metafizik, matematik ve mantık bilimlerinde, aksiyomlar çalışılan sistem içinde doğru olmalıdır ve birbirleriyle çelişmemelidir. Aksi takdirde, aksiyomlara dayalı olarak ulaşılan sonuçlar geçerli olmayacaktır. İdeal olanı, önce önermeler ifade edilir daha sonra önermenin doğruluğunu gösterecek hatasız ispatlar yapılır. $\mathrm{Bu}$ nedenle, metafizik, matematik ve mantığın doğruları, içinde çalışılan sisteme-dayalıdır. Bununla birlikte, bu bilim dalları arasında önemli bir fark vardır: Metafizik, evrene ilişkin iddialar ortaya koyarken, matematik ve mantık böyle bir iddiada bulunmaz. Matematik ve mantık, bir soyutlama inşa eder. Matematik, veri tercihlerini ortaya koymaz. Bir matematikçi, matematik yaparken fiziksel gerçeklik hakkında herhangi bir şey söylemez. Bunun yerine matematik, kavramlar arasındaki ilişkileri inceler. Böylece matematik ve mantık, evrene bağlı değildir. Diğer taraftan bilim, evrendeki ilişkileri belirleyen düzenlilik ilkesiyle ilgilenir. Fakat, deneysel yaklaşıma dayalı bilim şimdiye kadar, nihai nedenleri derinlemesine araştırma ve ortaya çıkarma noktasında yetersiz kalmıştır. Matematik bir kavramsal araç olarak, bilimin başarısız kaldığı bu noktada yani nihai nedenleri açıklamada yardımcı olmaktadır ve bilime, metafiziğe ilişkin sorunları/alanları bildirmede ve göstermede iyi imkânlar sunmaktadır. Bu olaylar, bilimsel bulgular olarak "Evren, yaşam, etik vb. nedir ve nereden gelmiştir?" şeklinde varlığın doğasına yönelik sorulara uygulanabilir (Carter, 2003).

\section{Metafizik, Fizikötesi ya da Fizik Üstü Müdür?}

Metafizik kavramı, genel olarak günlük hayatta ve bilim dünyasında fizikötesi kelimesi ile ifade edilmektedir. Buradaki fizikötesi kelimesi, fizik ve ötesi sözcüklerinin birleşiminden oluşmuştur. Metafizik kavramının ön eki olan meta sözcügüünün etimolojik anlamı ve bu ön eki alan kavramlar, farklı disiplinler oluşturmaktadır. Cevizci(2003), bu kavramları şu şekilde tanımlamaktadır:

Meta: Batı dillerinde, aşmayı, daha üst düzeyde ele almayı ifade eden terim. Bir ismin, belli bir disiplinin önüne geldiği zaman, o disiplinin temel özelliklerini ve problemlerini araştırmayı, incelemeyi ve çözmeyi ifade eden önek. 
Buna göre, meta öneki bir disiplinin önüne geldiğinde, oluşan üst disiplin, konu aldığı disiplinin temellerini analiz eder, onun özünü ve kabullerini daha bir üst kavramsal düzeyde gözler önüne serer. Başka bir deyişle, çağdaş düşüncede meta öneki bir şey, bir teori, bir disiplin hakkında olma durumunu, bir disiplin ya da araştırma alanını bir üst dil veya düzeyde ele alma durumunu ifade eder.

Metabilim: Bilimi konu alan, bilimi açıklayıp anlaşılır kılmayı amaçlayan bilim üstü disiplin; bilim hakkında bilim üzerine olan bilim.

Metaetik: Etik alanının üzerine çıkarak ahlakın bizatihi kendisi hakkında konuşan, ahlaklı olmanın doğasını, etiğinin temel karakteristiklerini, ahlak dilini çözümleyen etik türü.

Metamatematik: Formel bir matematik sistemini konu alan, bir matematik teorisinin önermelerinin türetilebilirliğini, çıkarsanabilirliğini vb. konu alan araştırma türü; matematik için temeller sağlama teşebbüsü olarak, matematiğin tutarlılığını, matematiksel kanıtları başka bir matematiksel kalkülün konusu yapmak suretiyle ortaya koyma projesi ve program1.

Metafelsefe: Felsefenin felsefesi. Felsefenin doğası, amaçları, yöntemleri ve temel kabulleriyle ilgili olan felsefe ya da teori.

Metafizik: Farklı metafizik anlayışları benimseyenler, metafiziğin temel özellerini şu şekilde sıralar: 1. Metafizik, var olana ilişkin bir araştırmadır. 'Neyin var olduğu' sorusunun kendisinin temel sorusu olduğu metafizik, var olana ilişkin genel görüşü tahkik ederken, neyin gerçekten var olduğunu göstermeyi amaçlar. 2.Metafizik, varlığa ilişkin genel bir araştırmadır. 3. Metafizik kendine ve kendi başına var olan gerçekliği, her şeyin varoluşu için kendisine bağlı olduğu, bağımsız ve kendi kendisini belirleyen varlığg; her tür varoluşun kaynağı ya da nedeni olan aşkın bir gerçekliği ele alan disiplindir. 4. Metafizik, tüm disiplin ya da araştırma alanları içinde en temel, en geniş kapsamlı olan araştırma alanıdır. Temeldir, çünkü diğer araştırma türlerine konu olan şeylerin nihai ve en yüksek doğalarını ele alır. En kapsamlıdır, çünkü metafizikçinin ele aldığı varoluş ve gerçeklik, aktüel ve potansiyel varlıkla ve nihayet nedensellikle ilgili sorular özel bilimlerin sınırlarını aşan ve tüm alanlar ve konular için geçerli olan soru ve problemlerdir.

Yukarıda verilen tanımlardan da anlaşılacağı üzere, meta ön eki herhangi bir disiplinin veya bir kavramın önüne geldiği zaman, o disiplin veya kavramın temel parametrelerinin “özünü” ve “kabuller”ini bozmadan daha üst bir kimlik kazandırmaktadır. Meta ön eki ile birlikte yazılan kavram, “üst”, “kapsam”, “üzerine” gibi bir anlam yüklenmekte ancak "öte”, “öteleme” gibi bir anlam vermemektedir. Bu bağlamda, matematiksel öteleme paradigması aracılığıyla metafizik kavramına yaklaşım örnekleri aşağıda verilmiştir. 


\section{Matematiksel Kavramlar ve Öteleme Paradigması ile Metafizik Kavramına Yaklaşım}

Bu kısımda, metafizik kavramının anlaşılması ve özelliklerinin belirlenmesinde, matematiksel kavramlar ve öteleme paradigmasından yararlanılmış ve bu kapsamdaki örneklere ve tartışmalara yer verilmiştir.

\section{$X Y$ - Düzleminde Öteleme Yardımıyla $X Y=R^{2}$ Düzleminde Orijin Merkezli Dairenin Ötelenmesi}

Öteleme, bir denklemin grafiğginin h birim sağa ve k birim yukarıya ötelendiğinde, ötelenmiş eğrinin denkleminin, orijinal denklemde $\mathrm{x}$ yerine $\mathrm{x}$-h ve y yerine $\mathrm{y}$-k koymak suretiyle elde edilmesidir (Edwards \& Penney, 2001). Bu bağlamda, $\mathrm{R}^{2}=\mathrm{XY}$ düzlemindeki her bir noktanın $\mathrm{h}$ birim sağa ve $\mathrm{k}$ birim yukarıya taşınmak suretiyle ötelendiği kabul edilsin. $\mathrm{Bu}$ durumda, düzlemin her bir $(\mathrm{x}, \mathrm{y})$ noktası $(\mathrm{x}+\mathrm{h}, \mathrm{y}+\mathrm{k})$ noktasına taşınmış olur. Böylece $(0,0)$ merkezli ve $r$ yarıçaplı $x^{2}+y^{2} \leq r^{2}$ dairesi, $(h, k)$ merkezli ve $r$ yarıçaplı $(x-h)^{2}+(y-k)^{2} \leq r^{2}$ dairesine ötelenmiş olur. Burada, $x^{2}+y^{2} \leq r^{2}$ dairesi A kümesi, $(\mathrm{x}-\mathrm{h})^{2}+(\mathrm{y}-\mathrm{k})^{2} \leq \mathrm{r}^{2}$ dairesi de B kümesi olarak isimlendirilsin. Buna göre, bu iki kümenin arakesiti boştur, yani $\mathrm{A} \cap \mathrm{B}=\varnothing$ tur. Dolayısıyla, $\mathrm{A}$ ve $\mathrm{B}$ kümeleri ayrıktır. Burada, A kümesi fizik, B kümesi ise fizikötesi olarak isimlendirilebilir (bkz. Şekil 2.1).

Şekil 1. $X Y=I^{2}$ Düzleminde Orijin Merkezli Dairenin Ötelenmesi

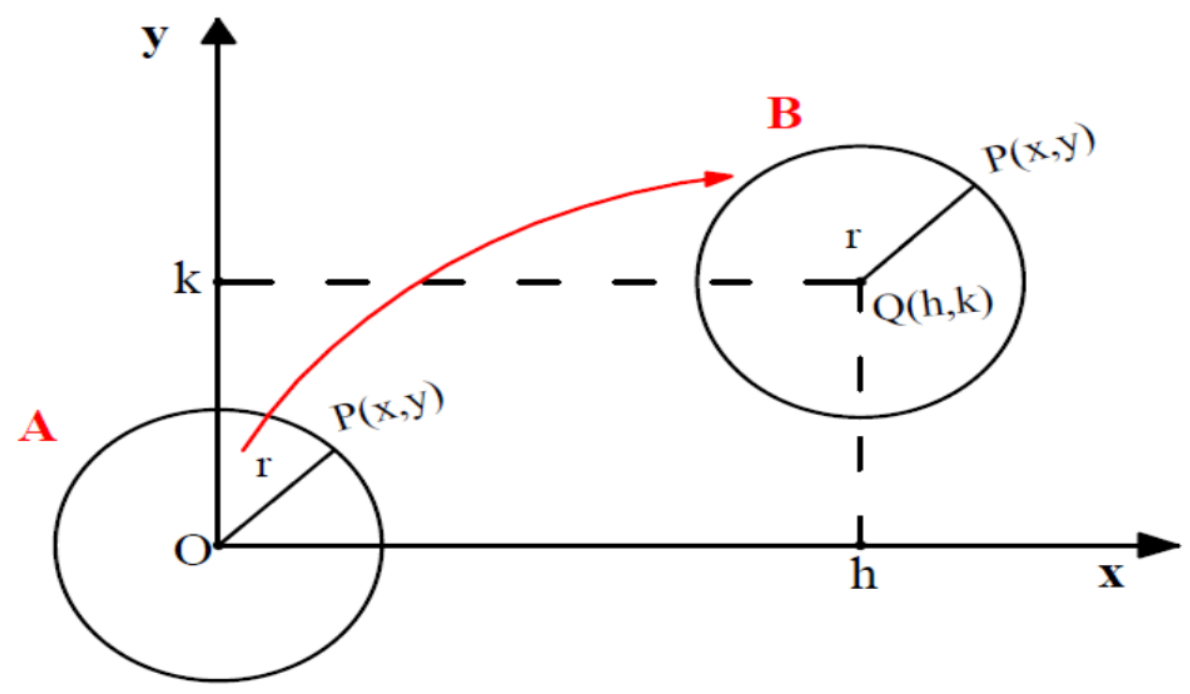

\section{Düzlemdeki Noktaların Öteleme Fonksiyonu Altındaki Görüntüleri}

$\mathrm{XY}$ - düzlemindeki bir $\mathrm{P}(\mathrm{x}, \mathrm{y})$ noktasının $\mathrm{P}^{\prime}(\mathrm{x}+\mathrm{h}, \mathrm{y}+\mathrm{h})$ noktasına ötelenmesi durumunda, bu iki noktanın arakesiti boştur. Yani, $\mathrm{P} \cap \mathrm{P}^{\prime}=\varnothing$ olur. Dolayısıyla bu iki nokta ayrıktır. $\mathrm{P}^{\prime}$ noktası, $\mathrm{P}$ noktasının ötelenmiş hali olduğundan burada, P noktası fizik, P' noktası ise fizikötesi olarak isimlendirilebilir (bkz. Şekil 2.2). 
Şekil 2. Düzlemdeki Bir Noktanın Öteleme Fonksiyonu Altındaki Görüntüsü

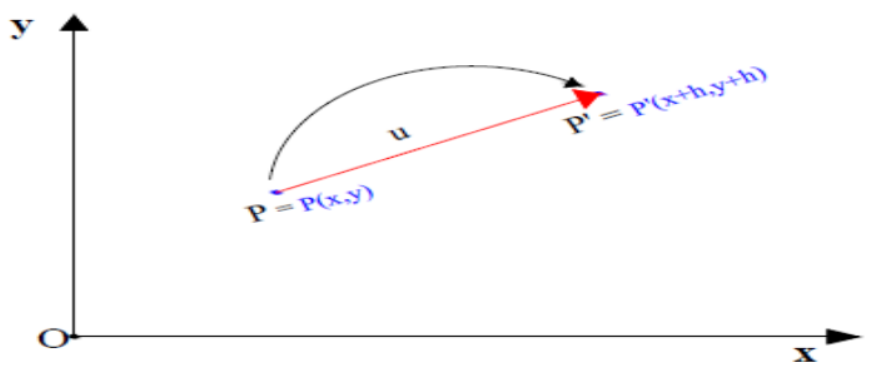

Düzlemdeki noktalara karşılık gelen noktaları, öteleme fonksiyonu yardımıyla elde etmek için Şekil 2.3 ' te gösterilen dönüşümün gerçekleştirildiği düşünülsün. $O$ zaman, düzlemde D, E, F, G noktaları, $\overrightarrow{\mathrm{u}}: \mathrm{IR}^{2} \rightarrow \mathrm{IR}^{2}(\mathrm{x}, \mathrm{y}) \rightarrow(\mathrm{x}+\mathrm{h}, \mathrm{y}+\mathrm{h})$ öteleme fonksiyonu yardımıyla D', E', F', G' noktalarına ötelenir. Burada, her bir nokta ile ötelendikleri noktaların arakesitleri boştur. Yani ortak noktaları yoktur. Dolayısıyla, $\mathrm{D} \cap \mathrm{D}^{\prime}=\varnothing, \mathrm{E} \cap \mathrm{E}^{\prime}=\varnothing, \mathrm{F} \cap \mathrm{F}^{\prime}=\varnothing$ ve $\mathrm{G} \cap \mathrm{G}^{\prime}=\varnothing$ tur (bkz. Şekil 2.3).

Şekil 3. Düzlemdeki Noktaların Öteleme Fonksiyonu Yardımıyla Ötelenmesi

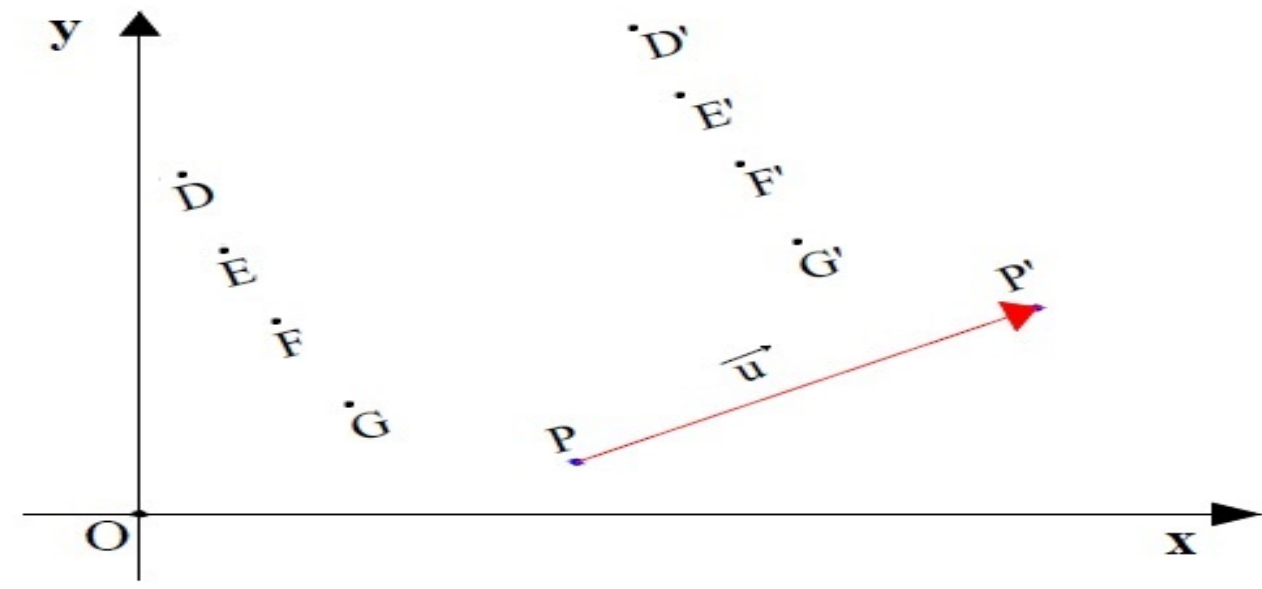

\section{Öteleme Fonksiyonunun Matris Yardımıyla İfade Edilmesi}

Öteleme dönüşümü, uzaklık koruyan bir fonksiyon olup, matematikte izometri olarak adlandırılır. Öteleme, bir fonksiyon olduğu için öteleme fonksiyonunu tam anlamıyla anlamlandırabilmek için burada öncelikle fonksiyon kavramını tanımlamak gereklidir. Fonksiyon çeşitli şekillerde ifade edilebilmesine rağmen, bu çalışmada fonksiyon kavramı ile birbiriyle özel bir şekilde eşleşen ikililer kümesi kastedilmiştir. $\mathrm{Bu}$ özel eşleşmeye göre, ikililerden herhangi ikisi aynı ilk bileşene sahip olamaz. Yani bir fonksiyon, ikililerden oluşan bir kümedir öyle ki bu ikililerin hiçbiri aynı ilk bileşene sahip olmaz (Zembat, 2013) şeklinde tanımlanabilir. Bu bağlamda; Martin (1982), ötelemeyi bir vektör yardımıyla düzlemdeki tüm noktaları yine düzlemdeki 
noktalarla eşleştiren bir dönüşüm (fonksiyon) olarak tarif etmektedir. Buradan hareketle, matematiksel olarak öteleme dönüşümü, $\vec{v}=(a, b)$ vektörüne bağlı olarak aşağıdaki şekilde bir fonksiyon olarak ifade edilmektedir (Zembat, 2013).

$$
\begin{gathered}
\mathrm{T}_{\overrightarrow{\mathrm{V}}}: \mathrm{IR}^{2} \rightarrow \mathrm{IR}^{2} \\
(\mathrm{x}, \mathrm{y}) \rightarrow(\mathrm{x}+\mathrm{a}, \mathrm{y}+\mathrm{b})
\end{gathered}
$$

Düzlemde her bir noktaya bir sayı ikilisi ve her bir sayı ikilisine de bir nokta karşılık gelir. Düzlemdeki her bir nokta bir matrisle ifade edilebilir. Bir ABC üçgeni alınsın. Bu üçgenin köşeleri; $\mathrm{A}(1,4), \mathrm{B}(3,6), \mathrm{C}(5,3)$ olmak üzere, $\vec{u}=(1,-4)$ vektörü , $\mathrm{T}_{\overrightarrow{\mathrm{V}}}$ : $(\mathrm{x}, \mathrm{y}) \rightarrow$ $(\mathrm{x}+1, \mathrm{y}-4)$

öteleme fonksiyonu yardımıyla aşağıdaki geometrik tasvir ortaya çıkar.

Şekil 2.4'te geometrik gösterimi verilen öteleme fonksiyonu matrisler yardımıyla şu şekilde yazılabilir: $\stackrel{\Delta}{(\mathrm{ABC}}) \cap\left(A^{\prime} B^{\prime} C^{\prime}\right)=\varnothing$

Şekil 4. Öteleme Fonksiyonunun Geometrik Gösterimi

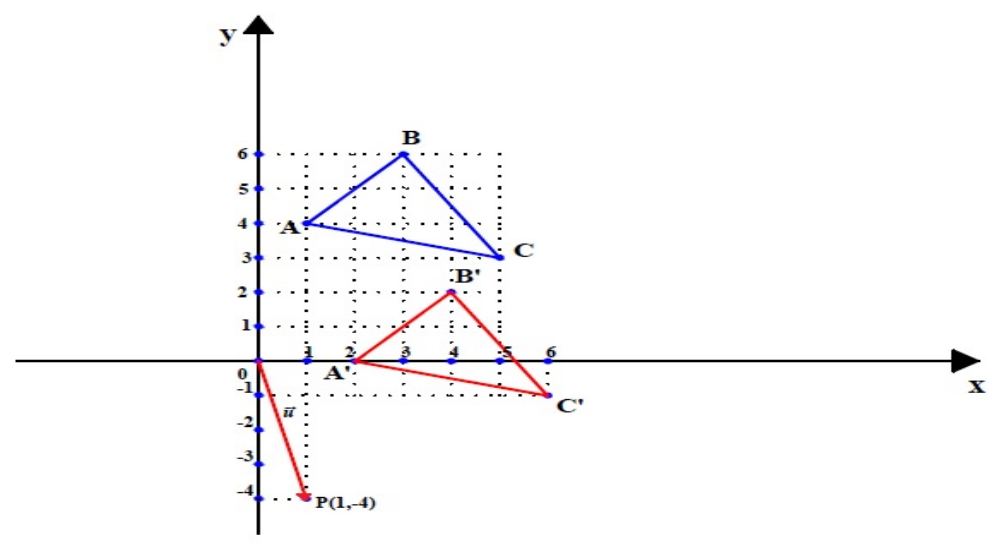

$\mathrm{T}_{\overrightarrow{\mathrm{V}}}:(\mathrm{x}, \mathrm{y}) \rightarrow(\mathrm{x}+1, \mathrm{y}-4)$

öteleme fonksiyonu yardımıyla, köşeleri $\mathrm{A}(1,4), \mathrm{B}(3,6)$ ve $\mathrm{C}(5,3)$ olan $\mathrm{ABC}$ üçgeni, köşeleri $\mathrm{A}^{\prime}(2,0), \mathrm{B}^{\prime}(4,2)$ ve $\mathrm{C}^{\prime}(6,-1)$ olan $\mathrm{A}^{\prime} \mathrm{B}^{\prime} \mathrm{C}^{\prime}$ üçgenine dönüşmüştür. $\mathrm{ABC}$ üçgeni ile $\mathrm{A}^{\prime} \mathrm{B}^{\prime} \mathrm{C}^{\prime}$ üçgeninin hiçbir ortak noktası yoktur. Dolayısıyla bu iki üçgenin arakesiti boştur. Yani, $\stackrel{\Delta}{A B C}) \cap\left(A^{\prime} B^{\prime} C^{\prime}\right)=\varnothing$ olur. 
$\mathrm{XY}=\mathbf{R}^{2}$ Düzleminde Orijin Merkezli Bir Dairenin Üst Kümesini Oluşturma $A=x^{2}+y^{2} \leq r^{2}$

$$
B=(x+h)^{2}+(y+k)^{2} \leq \rho^{2}
$$

Şekil 5. $X Y=R^{2}$ Düzleminde Orijin Merkezli Bir Daire Ve Üst Kümesi

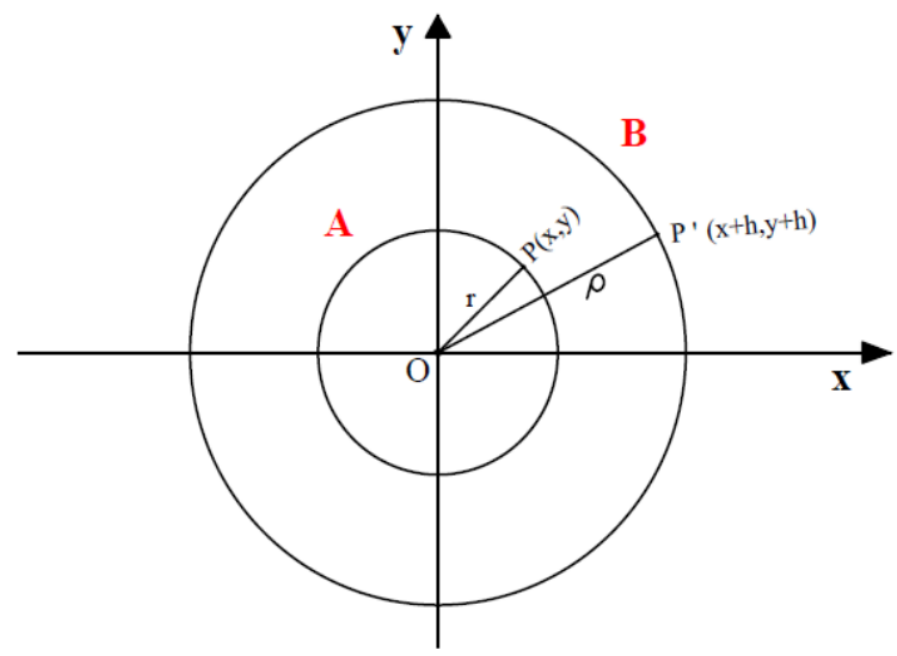

Şekil 2.5' ten de görüldüğü gibi, B kümesi A kümesini kapsar. Yani, B kümesi üst

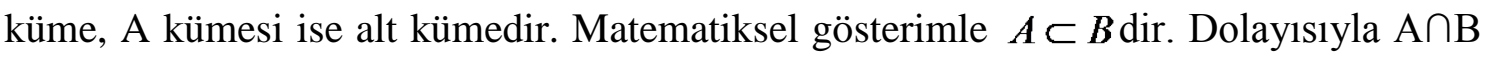
$=\mathrm{A} \neq \varnothing$ dir. Yani A ile $\mathrm{B}$ kümelerinin arakesiti (kesişimi), boştan farklıdır ve bu iki küme ayrık değildir. Burada, A kümesi fizik, B kümesi ise metafizik olarak isimlendirilebilir.

Metafizik Kavramının Lineer Bağımılılık ve Lineer Bağımsızlık Açısından Değerlendirilmesi

Şekil 6 a) Lineer Bağımlı İki Vektör

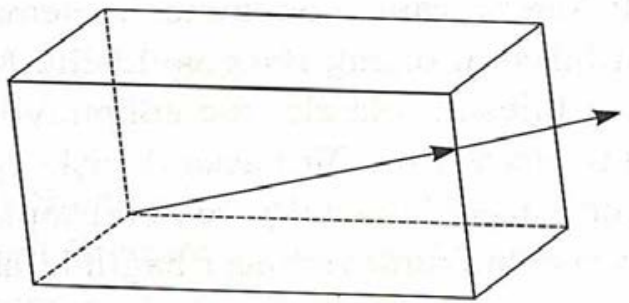

Uyarlandĭ̆ı yayın. (Lipschutz, 1990, s. 148)
Şekil 6 b) Lineer Bağımlı Üç Vektör

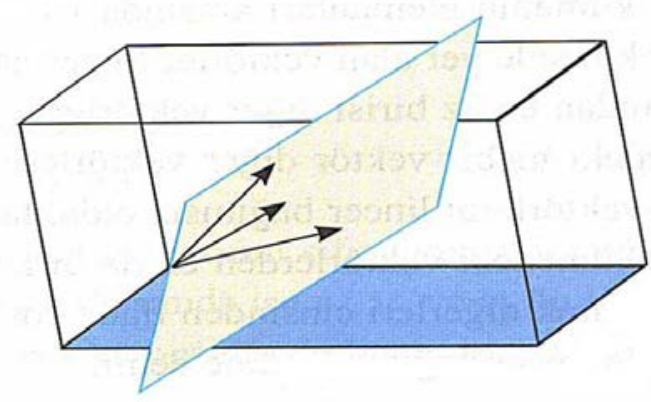


$\mathrm{R}^{2}$ uzayında iki vektör lineer bağımlı ise bu vektörler aynı doğru üzerinde bulunurlar. Eğer bu iki vektör aynı doğru üzerinde değil ise lineer bağımsızdırlar (bkz, Şekil 2.6a-b). Buradan hareketle aşağıdakiler söylenebilir:

$\mathrm{v}_{1}$ ve $\mathrm{v}_{2}$ vektörleri lineer bağımlı ise $\mathrm{v}_{1} \cap \mathrm{v}_{2} \neq \varnothing$

$\mathrm{v}_{1}$ ve $\mathrm{v}_{2}$ vektörleri lineer bağımsız ise $\mathrm{v}_{1} \cap \mathrm{v}_{2}=\varnothing$ tur.

$\mathrm{R}^{3}$ vektör uzayında verilen üç vektör $\left(\mathrm{v}_{1}, \mathrm{v}_{2}, \mathrm{v}_{3}\right)$ lineer bağımlı iseler bu üç vektör aynı düzlemde bulunurlar. Eğer üç vektör lineer bağımsız ise vektörlerin her üçü aynı anda ve aynı düzlem üzerinde bulunamazlar. Yani, $\left(\mathrm{v}_{1}, \mathrm{v}_{2}, \mathrm{v}_{3}\right)$ vektörleri lineer bağımlı iseler

$\mathrm{v}_{1} \cap \mathrm{v}_{2} \cap \mathrm{v}_{3} \neq \varnothing$ dir. Diğger taraftan, $\left(\mathrm{v}_{1}, \mathrm{v}_{2}, \mathrm{v}_{3}\right)$ vektörleri lineer băğmsız iseler $\mathrm{v}_{1} \cap \mathrm{v}_{2} \cap \mathrm{v}_{3}=$ $\varnothing$ tur.

Şekil 7. $\mathrm{R}^{2}$ ve $\mathrm{R}^{3}$ deki Standart Birim Vektörleri
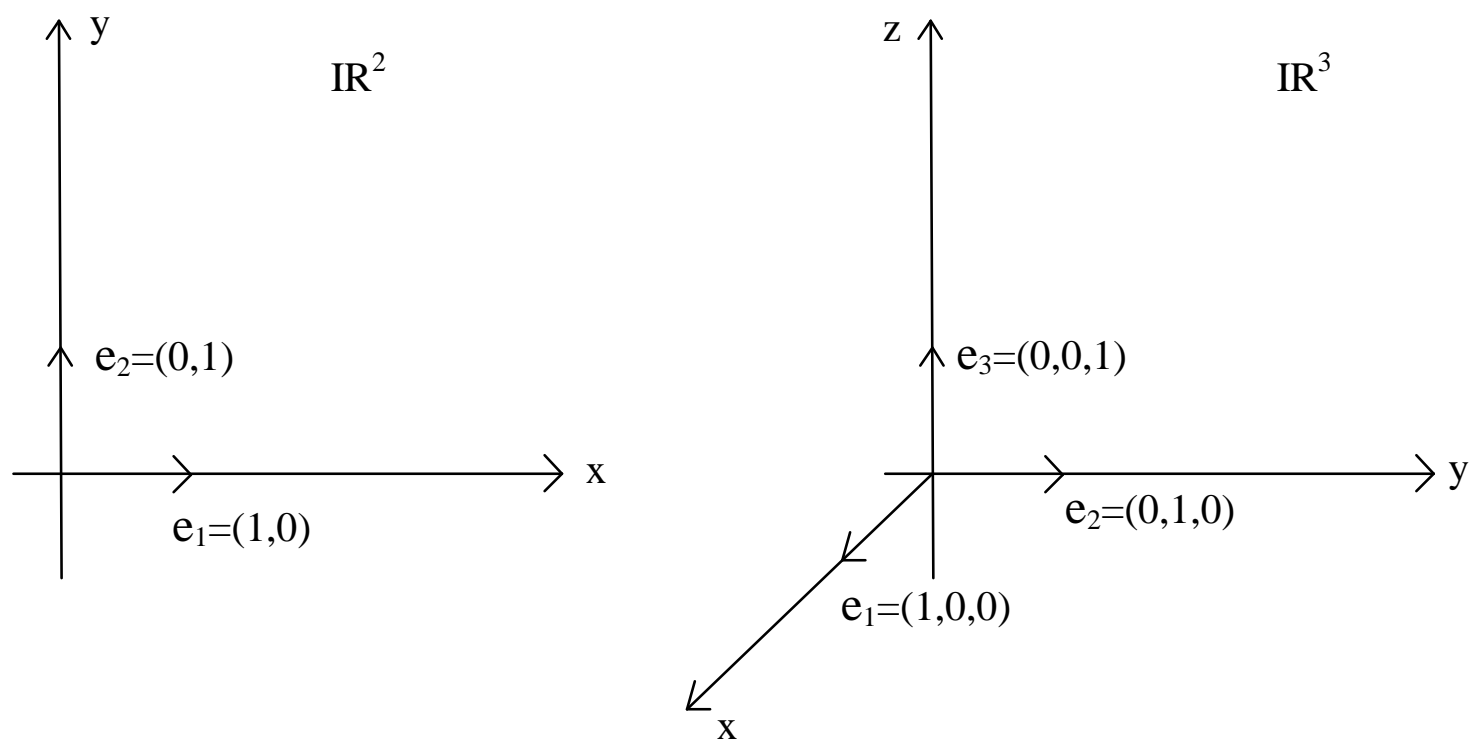

$\mathrm{R}^{2}, \mathrm{R}^{3}, \ldots, \mathrm{R}^{\mathrm{n}}$ vektör uzaylarındaki birim vektörlerinin oluşturduğu matrislerin basamak biçimi aşağıdaki şekilde gösterilebilir:

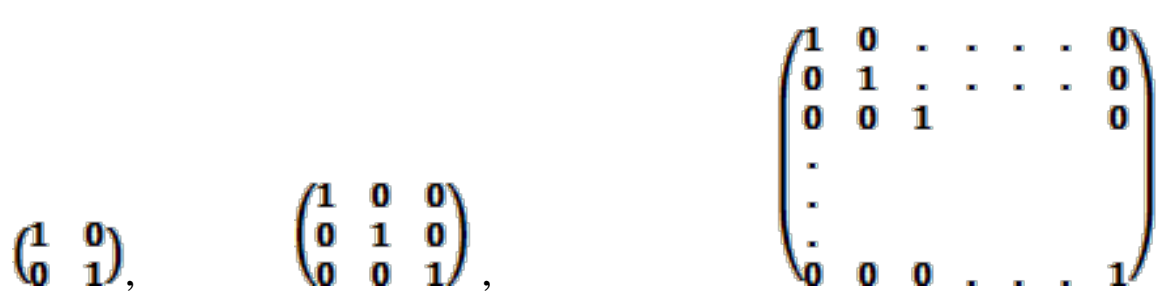


$\mathrm{R}^{2}, \mathrm{R}^{3}$ ve $\mathrm{R}^{\mathrm{n}}$ deki standart birim vektörleri, Şekil 2.7 den de görüldüğü gibi lineer bağımsızdırlar. Çünkü $\mathrm{R}^{2}$ vektör uzayında $\mathrm{e}_{1} \cap \mathrm{e}_{2}=\varnothing, \mathrm{R}^{3}$ vektör uzayında $\mathrm{e}_{1} \cap \mathrm{e}_{2} \cap \mathrm{e}_{3}=\varnothing$, $\ldots, \mathrm{R}^{\mathrm{n}}$ vektör uzayında $\mathrm{e}_{1} \cap \mathrm{e}_{2} \cap \ldots \cap \mathrm{e}_{\mathrm{n}}=\varnothing$ olur. Arakesitleri boş olan bu lineer bağımsız vektörlerin ortak hiçbir noktaları yoktur.

Şimdi, lineer bağımlı vektör uzayına ilişkin aşağıdaki örnek verilsin.

$\mathrm{R}^{2}$ de $\mathrm{V}_{1}=(1,2), \mathrm{V}_{2}=(2,4)$ vektörleri lineer bağımlıdır.

Çünkü,

$$
\begin{aligned}
& \mathrm{C}_{1}(1,2)+\mathrm{C}_{2}(2,4)=(0,0) \\
& \left(\mathrm{C}_{1}+2 \mathrm{C}_{2}, 2 \mathrm{C}_{1}+4 \mathrm{C}_{2}\right)=(0,0) \\
& \Rightarrow \mathrm{c}_{1}+2 \mathrm{c}_{2}=0 \\
& \Rightarrow \mathrm{c}_{1}=-2 \mathrm{C}_{2} \\
& 2 \mathrm{c}_{1}+4 \mathrm{C}_{2}=0
\end{aligned}
$$

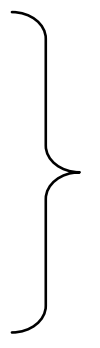

$\mathrm{C}_{1}=2, \mathrm{C}_{2}=-1$ sistemin çözümü olup, $\mathrm{V}_{1}$ ve $\mathrm{V}_{2}$ vektörleri lineer bağımlıdır. Lineer bağımlı vektörlerin arakesiti boş değildir. Yani, $v_{1} \cap v_{2} \neq \varnothing$ dır. Bu sonuçtan hareketle, lineer bağımlılık ve lineer bağımsızlık açısından fizik ve metafizik kavramları arasındaki ilişki için ilintiye baktığımız zaman şu söylenebilir; Eğer metafizik, fizikötesi kavramıyla tanımlanıp fizikle hiçbir bağımlılığı olmayan bir kavram şeklinde ifade edilirse yani, fizik $\mathrm{V}_{1}$ vektörü, metafizik $\mathrm{V}_{2}$ vektörü olarak alınırsa ve bu iki vektör de lineer bağımsız oldukları için Fizik $\cap$ Metafizik $=\varnothing$ olur.

\section{Sonuç ve Tartışma}

Yukarıda verilen Şekil 2.1' de görüldüğü gibi, matematiksel öteleme prensibi çerçevesinde bakıldığında, esas fonksiyonun belirlediği $(0,0)$ merkezli ve $r$ yarıçaplı $\mathrm{x}^{2}+\mathrm{y}^{2} \leq \mathrm{r}^{2}$ dairesi ile ötelenen $(\mathrm{h}, \mathrm{k})$ merkezli ve $\mathrm{r}$ yarıçaplı $(\mathrm{x}-\mathrm{h})^{2}+(\mathrm{y}-\mathrm{k})^{2} \leq \mathrm{r}^{2}$ dairesinin tamamen ayrık kümeler olduğu ve bu iki kümenin arakesitinin $\varnothing$ (boş) küme olduğu görülmektedir. Benzer şekilde, Şekil 2.2' yi incelediğimizde de xy- düzlemindeki p (x,y) noktasının öteleme fonksiyonu ile $\mathrm{Q}=\mathrm{Q}(\mathrm{x}+\mathrm{h}, \mathrm{y}+\mathrm{h})$ noktasına ötelendiği görülmektedir. $\mathrm{Bu} \mathrm{p}(\mathrm{x}, \mathrm{y})$ noktası ile ötelenen $\mathrm{Q}(\mathrm{x}+\mathrm{h}, \mathrm{y}+\mathrm{h})$ noktalarının da ayrık kümeler olduğu ve ayrık olan bu iki kümenin de arakesitlerinin boş (Ø) küme olduğu aşikârdır. Eğer kümeler ayrık ise arakesitleri boştur. Dolayısıyla ortak hiçbir noktaları yok demektir.

Eğer metafizik kavramı, fizikötesi şeklinde tanımlanırsa yukarıda matematiksel paradigmayla açıklanan öteleme fonksiyonu prensibi gereğince, fizik ile metafizik kavramlarının arakesiti boş olacaktır. Dolayısıyla bu iki kavram arasında hiçbir ortak nokta olmayacaktır. Oysa, fizik ile metafizik kavramları arasında hem kavramsal hem de pratiksel anlamda ortak noktalar vardır. Buradan, metafizik kavramının fizikötesi 
şeklinde tanımlanması hatalıdır. Çünkü, fizik ile metafizik kavramları, ayrık kavramlar değildir. Yani, Fizik $\cap$ Metafizik $\neq \varnothing$ tur.

Benzer şekilde, Şekil 2.4'teki öteleme fonksiyonu, matris yardımıyla bir geometrik gösterim oluşturmaktadır.

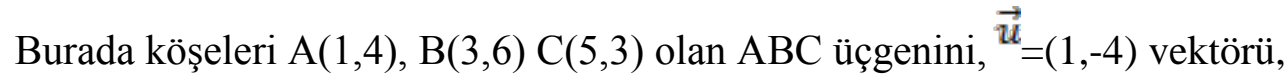

$\mathrm{O}_{\vec{u}}:(\mathrm{x}, \mathrm{y}) \rightarrow(\mathrm{x}+1, \mathrm{y}-4)$

Öteleme Fonksiyonu yardımıyla, köşeleri $A^{\prime}(2,0), B^{\prime}(4,2)$ ve $C^{\prime}(6,1)$ olan $A^{\prime} B^{\prime} C^{\prime}$ üçgenine dönüştü. $(\stackrel{\Delta}{A B C}) \cap\left(A^{\prime} B^{\prime} C^{\prime}\right)=\varnothing$ olur. Bu iki üçgen ayrıktır.

Burada, $A B C$ üçgenine fizik denirse $A^{\prime} B^{\prime} C^{\prime}$ üçgeni metafizik olarak adlandırılabilir. Buna göre, matematiksel paradigmayla Şekil 2.1, Şekil 2.2, Şekil 2.3 ve Şekil 2.4 teki öteleme fonksiyonları göz önüne alındığında ve meta önekinin etimolojik anlamı irdelendiğinde, bu önekin bir disiplinin önüne geldiğinde, o disiplinin özünü bozmadan daha üst, daha kapsayıcı bir anlam kazandırdığı görülmektedir. Bu durum, metafizik kavramının fizikötesi kavramıyla tanımlanamayacağını açıkça ortaya koymaktadır.

Diğer taraftan, Şekil 2.5'te verilen $A=x^{2}+y^{2} \leq r^{2}$ dairesi ile $B=(x+h)^{2}+(y+k)^{2} \leq$ $\rho^{2}$ dairesinin arakesiti boş $(\varnothing)$ değildir. Yani, $A \cap B=A=x^{2}+y^{2} \leq r^{2} \neq \varnothing$ tur. Dolayısıyla B kümesi, A kümesini kapsar veya B kümesi, A kümesinin üst kümesidir. A kümesine fizik denirse B kümesi metafizik olur. Çünkü, B kümesi A kümesini içeren, kapsayan en kapsamlı üst küme konumundadır. Buradan da açıkça görülmektedir ki, metafizik kavramı ancak fiziküstü kavramıyla ifade edilebilir. Buna göre, fizikötesi kavramı metafizik kavramını tam olarak karşılayamamaktadır. Şekil 2.6 (a), Şekil 2.6 (b) ve Şekil 2.7 den de görüldüğü gibi, lineer bağımsız vektörlerin bulundukları uzayda arakesitlerinin boş olduğu, yani hiçbir ortak noktalarının olmadığı, ancak lineer bağımlı vektörlerin arakesitlerinin boş olmadığı görülmüştü. Lineer bağımlılık ve lineer bağımsızlık açısından fizik ve metafizik kavramları arasındaki ilişkiye bakıldığında ise metafizik kavramının ancak fiziküstü kavramıyla anlam bulduğu görülmektedir.

\section{Kaynakça}

Carroll, J. W., \& Markosian, N. (2013). An introduction to metaphysics (4th edition). New York: Cambridge University Press.

Carter, B. M. (2003). Mathematics and metaphysics. Journal of the American Scientific Affiliation, 55(3), 159-165.

Cevizci, A. (2003). Felsefe terimleri sözlüğ̈̈ (2. baskı). İstanbul: Paradigma Yayınları.

Edwards, C., \& Penny, D. (2001). Matematik analiz ve analitik geometri (5. bask1) (çeviri editörü: Ömer Akın). Palme Yayıncılık.

Fine, K. (2012). What is metaphysics? Contemporary Aristotelian metaphysics. New York: Cambridge University Press. 
Handal, B. (2009). Philosophies and pedagogies of mathematics. Philosophy of Mathematics Education Journal, 17(1).

Lakatos, I. (1986). A renaissance of empiricism in the recent philosophy of mathematics. In T. Tymoczko (Ed.), New directions in the philosophy of mathematics (pp. 29-49). Boston: Birkhauser.

Lipschutz, S. (1990). Schaum serisinden lineer cebir teori ve problemleri (Çeviri Editörü: H. H. Hacısalihoğlu). Ankara: Nobel Yayın.

Loux, M. J. (2004). Metaphysics: A contemporary introduction. Canadian Philosophical Association, 43(04), 811-815.

Marvin, W. T. (1912). A First Book in Metaphysics. New York: Macmillan.

McGinnis, J. R. (1996, March 28-31). Researching the preparation of specialized mathematics and science upper elementary/middle-level teachers: The 2nd year report. Annual meeting of the National Science Teachers Association.

Mura, R. (1995). Images of mathematics held by university teachers of mathematics education. Educational Studies in Mathematics, 28(4), 385-399.

Taşdelen, İ. (2013). (Editör), Önsöz: Metafizik. Anadolu Üniversitesi Dergisi, Eskişehir.

Yaldır, H., \& Kiraz S. (2008). Nedensellik, bilim ve metafizik. Kaygı Dergisi, 11, 147163.

Zembat, İ. Ö. (2013). Tanımları ve tarihsel gelişimleriyle matematiksel kavramlar (1. baskı). Ankara: Pegem Akademi Yayıncılık. 